\title{
Serum concentrations of cartilage oligomeric matrix protein and bone sialoprotein in hip osteoarthritis: A one year prospective study
}

Thierry Conrozier, Tore Saxne, Charles Shan Sei Fan, Pierre Mathieu, Anne-Marie Tron, Dick Heinegård, Eric Vignon

\begin{abstract}
Objective-To evaluate serum concentations of cartilage oligomeric matrix protein (COMP) and bone sialoprotein (BSP) as predictors of disease progression in hip osteoarthrtitis (OA).

Methods-Forty eight consecutive patients, referred to hospital for symptomatic hip OA, (ACR criteria) were monitored in a one year prospective trial with radiographs and serum samples. The radiographs were graded for joint space narrowing, osteophytes, and sclerosis and the joint space width was measured by a digitised image analyser. Serum COMP and BSP were quantified by immunoassays.

Results-The COMP concentrations at baseline correlated with the joint space width at entry and with its yearly mean narrowing $(r=0.38, p=0.002)$ but not with joint space narrowing grade progression. The concentrations were higher in patients with bilateral hip OA $(p=0.03)$. The serum BSP concentrations at baseline were unrelated to $O A$ progression but correlated inversely to the osteophyte grade $(r=-0.36, p=0.004)$ and sclerosis grade ( $r=-0.42, \mathrm{p}=0.0004)$.

Conclusion-Serum COMP seems to be a surrogate marker of $O A$ and may be of interest for the detection of patients at risk of rapidly progressing disease in hip OA. Serum BSP changes seem to reflect alterations in the subchondral bone turnover in hip OA. Measurement of joint space width using a digitised image analyser is a sensitive way of assessing $\mathrm{OA}$ progression that facilitates evaluation of tissue markers in relation to anatomical changes in the joint.

(Ann Rheum Dis 1998;57:527-532)
\end{abstract}

Rheumatology

T Saxne

and Cell and

Molecular Biology

D Heinegård

Lund University, Lund, Sweden

Correspondence to: Dr T Conrozier, Service de Rhumatologie Pavillon 2B, Centre Hospitalier

Lyon-Sud, 69495, Pierre Benite cedex, France.

Accepted for publication 20 July 1998
Cartilage oligomeric matrix protein (COMP) and bone sialoprotein (BSP) have been shown to have potential as prognostic markers of OA progression..$^{1-3}$ COMP is a noncollagenous protein primarily isolated from the extracellular matrix of cartilage although the protein is not unique to this tissue. ${ }^{4}$ Thus, it has been found in bovine and equine tendon ${ }^{5}$ and in human knee joint meniscus. ${ }^{7}$ Furthermore, synovial cells can in vitro be stimulated to COMP production by transforming growth factor $\beta$ (TGF $\beta){ }^{8}$ COMP is a large, $M_{r} 435$ $\mathrm{kDa}$, acidic protein consisting of five subunits united close to their $\mathrm{N}$-termini forming a bouquet-like structure. ${ }^{4910}$ In adult cartilage COMP is preferentially located in the superficial, interterritorial matrix. ${ }^{4}$ The COMP concentrations are higher in synovial fluid than in serum, which suggests that it is locally produced in the joints. High concentrations of COMP have been detected in synovial fluid after knee trauma ${ }^{11}$ and increased serum COMP concentrations have been indicated to predict severe destruction in large joints in patients with rheumatoid arthritis. ${ }^{12}$ In knee OA, changes in serum COMP concentrations have been shown to predict joint space narrowing progression, and to correlate with the bone scintigraphic uptake of technetium diphosphonate. $^{23}$

BSP is a bone specific non-collagenous matrix macromolecule, polydisperse in size with an average $\mathrm{Mr}$ of $52500 .{ }^{13}$ The protein is enriched in the immediate subchondral layer of bone. ${ }^{14}$ It is increased in serum in patients with early radiographic signs of knee $\mathrm{OA}^{3}$ and in synovial fluid after knee trauma. ${ }^{15}$ In RA, BSP is increased in serum compared with healthy controls and synovial fluid concentrations correlate significantly to degree of knee joint damage. Serum concentrations show a similar variation, although not a significant association. ${ }^{16}$

A quantitative assessment of OA changes (that is, articular cartilage thickness, osteophytes, sclerosis, and cysts) is important in defining correlates in the evaluation of these new molecular markers. Anatomical changes can be visualised using plain radiographs or magnetic resonance imaging (MRI). MRI is a promising method but precise and reproducible measurements of cartilage and bone features are still in the developmental stage and are not fully validated. ${ }^{17}$ On the other hand, it seems that conventional radiography may be the most suitable method to assess articular cartilage thickness of the hips and knees in long term follow up studies. ${ }^{18} 19$ The most widely used method for radiographic evaluation of OA progression remains the Kellgren and 
Lawrence (KL) grading scale, ${ }^{20}$ which has been considered the "gold standard" for diagnosis and assessment of the progression of the condition. Alternatives to the $\mathrm{KL}$ scale are needed for evaluation of OA progression and particularly cartilage destruction. ${ }^{19}{ }^{21}$ The separate grading of different radiographic OA lesions has been used to improve sensitivity and reduce interobserver variability, ${ }^{22-24}$ but an accurate measure of progression requires direct measurement of joint space narrowing. New techniques have therefore been designed to quantitatively and reproducibly assess knee and hip joint space. ${ }^{25-28}$ Examples of such measures include special devices for microfocal radiography $^{25}$ and semiautomated digitised image analysers in combination with rigorous standardisation of the radiological procedure. ${ }^{29}$ The use of a computer image analysis system has been demonstrated to improve both sensitivity and reproducibility of the measurements. ${ }^{30} 31$ The purpose of this study was to evaluate serum concentrations of COMP and $\mathrm{BSP}$ as possible predictors of OA progression as determined by both semi-quantitative grading and automated measurement of radiographic changes in hip OA.

\section{Methods}

CLINICAL DATA

Forty eight patients ( 25 women and 23 men) referred to the department of rheumatology with symptomatic hip OA were recruited to this one year prospective study. All fulfilled the ACR criteria for hip OA. ${ }^{19}$ Only patients with superior femoral head migration (superolateral, superointermediate, and superomedial) were selected because of the difficulties for inferior or medial joint space narrowing (JSN) to be measured. Exclusion criteria were: total loss of radiographic joint space making it not measurable; total hip arthroplasty needed in the next 12 months; and hip OA secondary to alternative arthropathies (that is, infectious or inflammatory arthritis, hip injury, aseptic osteonecrosis, congenital abnormality such as congenital dislocation of the hip). At entry all patients underwent a full clinical history and examination to obtain the following information: height, weight, body mass index (BMI), disease duration and date of diagnosis, risk of hip joint overwork with regard to professional or sport activities (for example, regular heavy lifting or strenuous walking and running), clinical presence of polyarticular OA involvement (Heberden or Bouchard's nodes, clinical evidence of spine or knee OA ), smoking status. At entry and 12 months later, patients were asked for pain and function ( using Lequesne's index ${ }^{32}$ and a pain evaluation on a $100 \mathrm{~mm}$ visual analogue scale (VAS)) and current treatment (non-steroidal anti-inflammatory drugs (NSAIDs) and symptomatic slow acting drugs for OA (SYSADOA)).

RADIOGRAPHIC DATA

At each visit patients underwent radiography of the pelvis, by the same radiologist during the whole study, using an identical radiological procedure. Anteroposterior radiographs of the
Table 1 Osteoarthritis grading system for joint space narrowing, osteophytes, and sclerosis

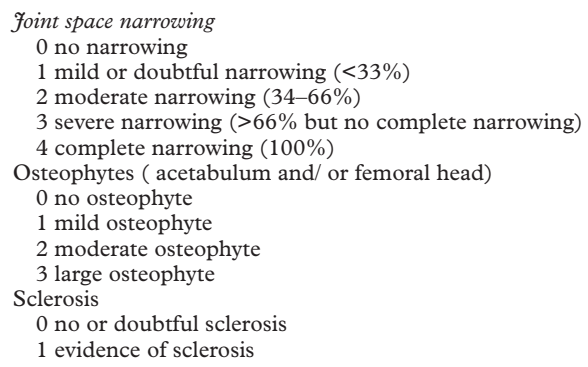

pelvis were perfomed in standing position with $20^{\circ}$ of internal rotation of the lower limbs. The focus-film distance was $100 \mathrm{~cm}$ and the beam was aligned to the top of pubic symphysis. Radiographic evaluation was made by a single experienced observer. The films were blinded for patient identity and date. OA radiographic changes were graded using a 5 point scale $(0$ to 4) for JSN, a 4 point scale (0 to 3) for osteophytosis and cysts, and a 2 point scale $(0-1)$ for sclerosis (table1). Previously, five readers, all rheumatologists and experienced in evaluating OA radiographs, reviewed a set of 20 selected radiographs for scoring separately OA features. The results were discussed to obtain a consensus about the scoring system. Four training sessions were performed. When all readers were familiarised with the grading system, the two best were selected for the evaluation of the reproducibility by using the intraclass coefficient of correlation from the reading of 30 radiographs of the hips.

Interobserver $\kappa$ values $(95 \% \mathrm{CI})$ obtained from a set of 30 hip radiographs were respectively $0.91 \quad(0.88,0.94), 0.79(0.71$, $0.87), 0.77(0.67,0.87)$, and $0.76(0.68,0.85)$. The diagnosis of hip OA was made according to the ACR criteria. ${ }^{19} \mathrm{~A}$ morphological evaluation of the hips was made to assess the patterns of femoral head migration within the acetabulum (that is, superolateral, superointermediate, superomedial) and to classify hip OA as hypertrophic $(\mathrm{H})$ or atrophic (A) according to presence or lack of osteophytes. ${ }^{33}$

Joint space width (JSW) was measured at the narrowest point using a digitised image analyser (Hologic). Before joint space measurement, the different films of a patients were placed side by side on a light box to determine the zone to analyse to measure the same zone in consecutive radiographs of a single patient. The device that was used to automatically measure joint space and the precise procedure have been described. ${ }^{30}$ After ensuring that the computer was correctly calibrated through repeated measurements of a line segment of known length (coefficient of variation (CV) $0.2 \%$ ) the radiograph of the joint to be analysed was placed on the view box and digitised at a resolution of 1280 pixels and 256 grey levels. Subtraction and magnification were performed to obtain a very clear outline of the joint space. The joint space contours were delineated with the mouse on the following margins: the superior convex margin of the femoral head and the inferior margin of the 
acetabulum. JSW was obtained by measuring the inter-bone distance at the narrowest point of the joint. The radius of the femoral head $(\mathrm{RH})$ was automatically given by the computer from three peripheral points drawn using the mouse. Because two radiographs of the same subject had to be compared, it was necessary to look for possible differences in magnification of the hip, and to make adequate corrections. This was done by the measurement of the RH of each film and then by calculating the ratio $\mathrm{RH}$ of the measured film/RH of the reference film. The intraobserver CV for repeated measurements of the same film was $1.2 \%{ }^{30}$ It was $2.9 \%$ for measurements of three radiographs of a single patient, performed by three radiologists at different days and without a particular standardised procedure, as described previously. ${ }^{28}$ Progression of JSN was calculated in $\mathrm{mm}$ per year, enabling determination of the yearly mean narrowing of the joint space $(\mathrm{YMN})$

BIOLOGICAL DATA

Blood samples were obtained at the baseline and after one year of follow up. C reactive protein (CRP) measurements were performed by immunonephelometry (N Latex CRP mono, Behringwerke AG, Marburg, Germany) with a threshold of detection of $5 \mathrm{mg} / \mathrm{l}$. Serum samples were stored at $-30^{\circ} \mathrm{C}$ until assayed for COMP and BSP.

Analyses of COMP and BSP were made without any knowledge of other clinical or radiographic characteristics of the patients. Serum concentrations of COMP were measured by enzyme linked inhibition immunosorbent assay (ELISA) as described. ${ }^{34}$ Briefly, human COMP was used for coating the microtitre plates and for producing a standard curve included in each plate. A polyclonal antiserum raised in a rabbit against bovine COMP was used as first antibody. Serum samples with known COMP concentrations were included in each plate to detect variability. The intraassay and interassay variabilitities were $5 \%$ and $8 \%$, respectively. The BSP assay was performed using an inhibition ELISA as described previously. ${ }^{13}$ Briefly, human BSP was used for coating the microtitre plates and for the standard curve. A polyclonal antiserum raised in a rabbit against human BSP was used for detection of BSP in the serum samples. Serum samples with known BSP concentrations were included in each plate. The intra-assay and interassay variabilities were $<10 \%$.

STATISTICAL ANALYSIS

In patients with bilateral hip OA only the most affected joint was selected for analysis of correlations between biological and radiographic variable. Correlations between continuous variables were performed using linear regression analysis or Spearman test as appropriate. Relation between continuous and qualitative variables were studied using analysis of variance. Factors found to be associated in univariate analysis were then studied using multivariate analysis and logistic regression analysis. Student's paired $t$ test was used to
Table 2 Characteristics of the 48 patients at entry in the study

\begin{tabular}{ll}
\hline Number of patients (female/male) & $48(25 / 23)$ \\
Age at entry in the study (y) & $56.4(14.1)$ \\
Age at onset of disease (y) & $51.1(14.1)$ \\
Lequesne index & $8.4(4.3)$ \\
Pain on the VAS (mm) & $48.2(25.4)$ \\
Joint space width (mm) & $1.80(1.04)$ \\
Body mass index & $25.8(4.3)$ \\
Other OA sites involved (yes/no) & $24 / 24$ \\
Bilateral hip OA (yes/no) & $18 / 30$ \\
Current NSAIDs consumption (yes/no/NA) & $22 / 19 / 7$ \\
Current SYSADOA consumption (yes/no/NA) & $18 / 23 / 7$ \\
Hip overwork (yes/no/doubtful) & $14 / 27 / 7$ \\
Smoking cigarettes (yes/no) & $15 / 33$ \\
Serum COMP ( $\mu \mathrm{g} / \mathrm{ml})$ & $7.7(1.2)$ \\
Serum BSP (ng/ml) & 143.3 \\
& $(27.3)$ \\
\hline
\end{tabular}

NA: not available. Data shown as numbers and mean (SD).

Table 3 Radiographic data at entry in the study

\begin{tabular}{ll}
\hline Joint space narrowing grade $(0 / 1 / 2 / 3)$ & $2 / 11 / 11 / 24$ \\
Osteophyte grade $(0 / 1 / 2 / 3)$ & $6 / 28 / 14 / 0$ \\
Joint space width $(\mathrm{SD})(\mathrm{mm})$ & $1.80(1.04)$ \\
Bone response (hypertrophic/atrophic/ & \\
$\quad$ undefinable) & $38 / 6 / 4$ \\
Femoral head migration (superolateral/ & \\
$\quad$ superointermediate/superomedial) & $29 / 12 / 7$ \\
\hline
\end{tabular}

compare values at baseline and end point. p Values $<0.05$ were considered significant.

\section{Results}

The demographic and clinical data at entry are summarised in table 2 and the initial radiographic data are summarised in table 3 . The mean (SD) JSW at entry was $1.8(1.04) \mathrm{mm}$ (median: $1.65 \mathrm{~mm}$, range $0.5-4.0$ ). The yearly mean narrowing was $0.52(0.45) \mathrm{mm} /$ year (median 0.49 , range $0-2$ ). It was correlated to JSW at entry $(r=0.66, \mathrm{p}<0.001)$.

COMP and BSP at baseline were mean (SD) $7.7(1.2) \mu \mathrm{g} / \mathrm{ml}$ ( range 5.4-10.5) and mean (SD) $143.3(27.3) \mathrm{ng} / \mathrm{ml}$ (range 100.8-250.5), respectively. The mean (SD) CRP was 7.5 (14.6) $\mathrm{mg} / \mathrm{ml}$ (range <5-34).

The COMP concentrations did not vary over time (mean (SD) $7.6(1.4) \mu \mathrm{g} / \mathrm{ml}$ at one year compared with mean (SD) $7.7(1.0) \mu \mathrm{g} / \mathrm{ml}$ at entry, $p>0.05)$, whereas the BSP concentrations increased during the year of follow up (mean (SD) $160.0(36.4) \mathrm{ng} / \mathrm{ml}$ at one year compared with mean (SD) $143(27.3) \mathrm{ng} / \mathrm{ml}$ at entry, $p=0.01)$. The COMP and BSP concentrations at entry correlated significantly $(r=$ $0.25, p=0.04)$.

The COMP concentrations at baseline correlated with JSW at entry $(r=0.40, \mathrm{p}=$ $0.001)$ and to YMN $(r=0.38, \mathrm{p}=0.002$ ) (fig $1)$. In contrast, after one year COMP concentrations did not correlate with YMN, while the correlation persisted with JSW $(r=0.36$, $\mathrm{p}=0.02)$. The correlation between COMP at entry and YMN is also shown in table 4 where COMP and BSP concentrations at baseline are grouped according to the tertiles of YMN. In support of this association, figure 2 shows that patients with serum COMP at baseline equal to or above $8.5 \mu \mathrm{g} / \mathrm{ml}$ had a $61.7 \%$ higher rate of narrowing than those with serum COMP below $8.5 \mu \mathrm{g} / \mathrm{ml}(\mathrm{p}=0.022)$. In contrast, the variations of serum COMP over time did not correlate with YMN. The 10 patients with the most marked YMN ( $>1 \mathrm{~mm} / \mathrm{year}$ ) had 


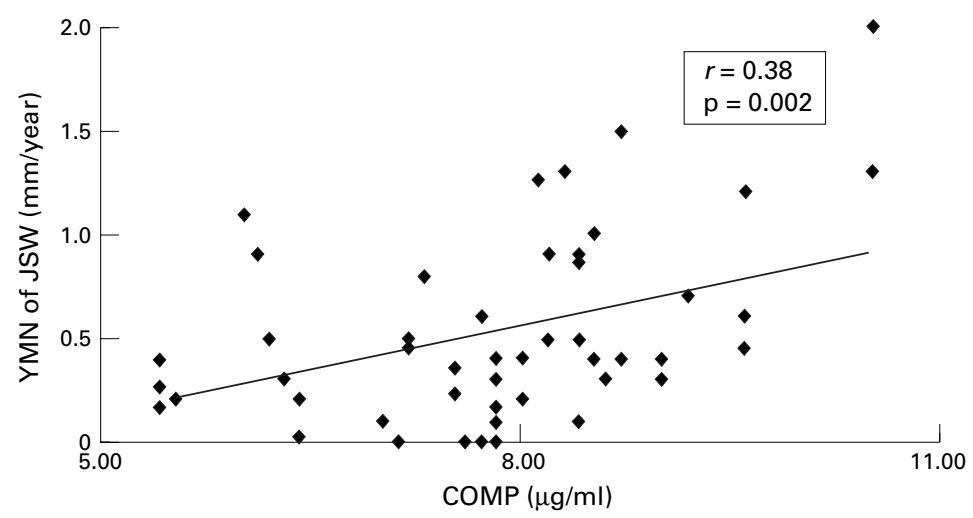

Figure 1 Correlation between serum COMP concentration at baseline $(\mu \mathrm{g} / \mathrm{ml})$ and radiographic yearly mean narrowing (YMN mm/year) in 48 patients with with hip $O A$.

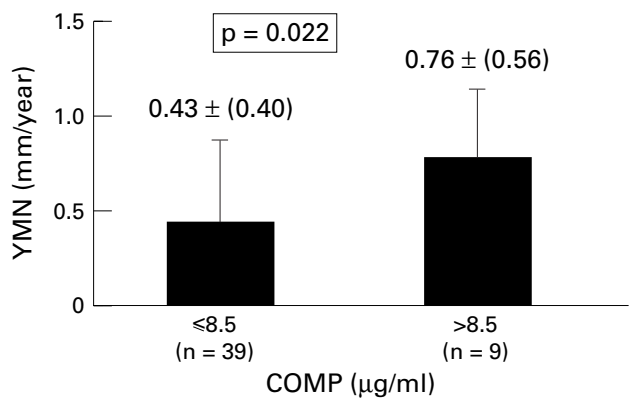

Figure 2 Radiographic yearly mean narrowing (YMN mm/year) according to the serum COMP concentration at baseline in 48 patients with in hip $O A$.

significantly higher serum COMP at entry, $\mathrm{p}=$ 0.01. The serum COMP concentrations were moderately higher in patients with bilateral hip OA than in patients with unilateral hip OA (mean (SD) 7.9 (1.2) compared wtih 7.2 (1.1) $\mu \mathrm{g} / \mathrm{ml}, \mathrm{p}=0.03)$. A tendency to higher serum COMP in subjects with superior femoral head migration compared with those with medial migration was also observed (mean (SD) 7.9 (1.2) compared with $6.7(1.1) \mu \mathrm{g} / \mathrm{ml}, \mathrm{p}=0.08)$. The COMP concentrations did not correlate to the radiographic pattern of bone response, osteophyte or sclerosis grade.

The BSP concentrations at entry correlated inversely with osteophyte grade $(r=-0.36, \mathrm{p}=$ $0.004)$, and sclerosis grade $(r=-0.42, \mathrm{p}=$ $0.0004)$ ). The BSP concentrations were higher in patients with atrophic OA than in patients with hypertrophic OA (mean (SD) 167.4 (14.5) compared with 139 (23.5) ng/ml, p = 0.006). The correlations remained significant at one year of follow up. The BSP concentrations were unrelated to JSW in $\mathrm{mm}$, JSN grade, and to YMN. Neither did variations of serum BSP over time correlate to YMN.

There was no correlation between levels of the tissue markers and JSN grade progression. Neither did baseline concentrations of COMP nor BSP relate to sex, age, disease duration,

Table 4 Serum COMP and BSP concentrations at baseline according to the rate of progression of joint space narrowing in hip

\begin{tabular}{llll}
\hline YMN (mm/year) & Number & COMP $(\mu g / m l)$ & BSP $(n g / m l)$ \\
\hline$<0.3$ & 16 & $7.22(1.12)(5.4-9.2)$ & $136.4(2.03)(105.2-173.0)$ \\
$0.3-0.6$ & 16 & $7.62(1.22)(5.4-9.6)$ & $146.2(34.0)(100.8-250.5)$ \\
$\geqslant 0.6$ & 16 & $8.31(1.24)(6.0-10.5)$ & $144.6(27.1)(101.7-180.4)$ \\
\hline
\end{tabular}

Data shown as mean (SD) and ranges. drug treatment, family history of OA, evidence of OA at other sites, smoking status, Lequesne index, VAS, and professional or sports activities. Serum COMP, but not serum BSP, correlated significantly to BMI, $r=0.47, \mathrm{p}=0.0001$. No correlation was found between BMI and JSW at entry, OA grade, or YMN.

Lequesne index $(8.4(4.3) v 8.2(4.9))$ and pain on the VAS (48.2 (25.4) $\mathrm{mm} v 50$ (19.4) $\mathrm{mm}$ ) as well as CRP serum concentrations (7.5 (14.6) v $6.2(7.9) \mathrm{mg} / \mathrm{l})$ did not vary significantly over the year of follow up (all p>0.05).

\section{Discussion}

The positive correlation between the COMP concentration at baseline and progression of JSN is the main finding in this study. Such a correlation between a single serum measurement of a tissue marker and future $\mathrm{OA}$ progression has not been demonstrated previously for a marker that may reflect cartilage turnover, albeit increasing COMP concentrations have been found to correlate to later disease progression in knee OA. ${ }^{2}{ }^{3}$ One reason for the observation of a correlation between serum COMP and anatomical changes in the joint could be that the method for measuring JSN progression, using a computer image analysis, is much more sensitive to small changes than commonly used semi-quantitative grading or inter-bone distance measurement using a ruler. ${ }^{21}{ }^{29}$ Our data suggest that a serum COMP concentration greater than $8.5 \mu \mathrm{g} / \mathrm{ml}$ is associated with a higher rate of JSN and supports the hypothesis that COMP is a surrogate marker of $\mathrm{OA}$, which could be particularly of interest for the detection of patients at risk of rapidly progressive disease. The finding of higher serum concentrations in patients with bilateral hip OA further supports that COMP in the general circulation reflects joint pathology. The effects on serum concentrations of COMP by putative contribution from extra-articular sources, have to be considered when interpreting changes in the circulating concentrations. However, the contribution from tendon is probably negligible in view of findings that even in race horses, who have exceptionally high COMP concentrations in their tendons, no increase was found in serum during tendinitis. ${ }^{35}$ Furthermore, it is not likely that the contribution from the synovial membrane is significant, as COMP concentrations in this tissue from RA and OA patients at joint replacement surgery are below detection level, that is less than $1 / 100$ of the level in cartilage (Saxne $\mathrm{T}$ and Heinegård $\mathrm{D}$, unpublished information). Further support for this view has recently been gained in experimental arthritis where increased serum COMP is not seen in the initial phase of arthritis when a marked inflammatory reaction is demonstrable but at a later time point when erosive changes are seen in the cartilage. ${ }^{36}$ However, it is tempting to speculate, in view of the findings of Recklies and coworkers, ${ }^{8}$ that in certain cases, for example, rapidly progressing forms with a marked synovitis, a contribution from synovial tissue might exist. This might reflect a low grade inflammation of the synovial tissue in certain cases of OA and would be consistent 
with the findings of a predictive value of hyaluronan in serum ${ }^{37}$ and also with the recent observation of a correlation between serum CRP and progression of knee ${ }^{38}$ and hip OA. ${ }^{39}$ However, in this study CRP assay was not performed using a high sensitivity method as done by Conrozier and colleagues. ${ }^{39}$

Another important finding in this study is the inverse correlation between serum concentrations of BSP and radiographic features of subchondral bone changes. Thus BSP seems to be a marker of bone turnover in OA in accordance with other findings. ${ }^{315}$ The increase in serum concentrations particularly in atrophic $\mathrm{OA}$ and its inverse correlation with the radiographic features of bone repair (osteophyte and sclerosis) suggest BSP may preferentially reflect subchondral bone osteopenia. These data are in accord with experimental findings showing BSP synthesis is stimulated by dexamethasoe and inhibited by $25 \mathrm{OH}$ vitamin D3. ${ }^{40}{ }^{41}$ In line with previous observations, we also found a significant correlation between serum COMP and BSP, which suggests a linkage between changes in the cartilage and bone turnover in the progressive tissue alterations in $\mathrm{OA}^{2{ }^{3}}$ The correlation may in part be explained by the much increased localisation of BSP at the cartilage-bone interphase, while other bone markers such as osteocalcin appear to be more evenly distributed throughout the bone matrix. ${ }^{14}$

The BSP concentrations did not correlate to radiographic measures of cartilage thickness, which is not unexpected in view of its tissue distribution. Nevertheless it is somewhat at variance with previous observations of increasing serum BSP in early stages of knee OA. ${ }^{3}$ However, in the previous study we likewise did not either find a correlation between baseline BSP and JSN. In contrast with previous studies we did not find any correlation between changes in COMP and BSP concentrations over time and progression of OA. ${ }^{23}$ On the other hand the previous studies did not show any correlation between baseline values and OA progression. ${ }^{2}{ }^{3}$ The explanations for these discrepancies are not clear but obviously there might be differences depending on the type of joint examined and also depending on the patient selection and the duration of the follow up. The patients in this study were all referred because of symptomatic OA of the hip, which differs from the Swedish knee OA study as it was a population based study. ${ }^{3}$ The duration of the follow up is probably of importance. It was only one year in this study while it reached five years in the knee OA trial. ${ }^{2}$ Furthermore most of the patients suffered from severe and advanced disease at inclusion (mean JSW 1.80 $\mathrm{mm}$ ) and it has been shown that serum COMP concentrations increase during the earliest stages of the condition, then decrease in advanced disease. ${ }^{34}$ The progression of JSN was very rapid in 10 of the patients in this study. This explains the high rate of progression in comparison with other reports. Nevertheless the 38 other patients appeared to progress at a rate similar to previously recorded data. ${ }^{42-45}$ The rapidly progressors dif- fered from the other patients only regarding age (69.4 (9) compared with 56.4 (14.1), $\mathrm{p}=0.02$ ) and COMP concentrations, but not with regard to JSW at entry, OA at other sites, and BMI. This may mean that in this study we have selected a subset of patients with severe OA, which might facilitate the identification of tissue morphological changes over a short time interval.

The inverse correlation between serum concentrations of both COMP and BSP and the radiographic severity of $\mathrm{OA}$ is a novel finding that extends earlier observations. Thus, lower synovial fluid concentrations of the proteins were seen in advanced knee OA as compared with less advanced stages as determined by a score combining radiographic and arthroscopic observations. ${ }^{15}$

The serum concentrations of COMP and BSP did not correlate to a number of studied demographic as well as clinical variables. This is not surprising, as no close link between such parameters and the tissue process is to be expected. The correlation between COMP and BMI is an exception. This association was not found in knee OA. ${ }^{2}$ However, Wolfe ${ }^{46}$ found a correlation between CRP and disease severity, and between CRP and BMI in 655 patients with OA of the knee or hip. Furthermore, an association between synovial fluid concentrations of the C-propeptide of type II collagen and BMI has also been reported. ${ }^{47}$ Obesity is known to be frequently associated with progressive OA and OA severity but the explanation for an association between overweight and serum markers of $\mathrm{OA}$ is presently unclear and additional studies are required to clarify it.

In conclusion, the findings of this study show that serum measurements of tissue derived macromolecules have potential as a tool in studies of the pathophysiology of OA and also for obtaining information on specific tissues including such of prognostic value. The combination of such measurements with sensitive instruments for assessing anatomical changes should facilitate future efforts to elucidate tissue responses and mechanisms of joint destruction in OA

We are grateful for technical assistance by Mrs Mette Lindell

and Mrs Stella Godeau. Grants were obtained from the French Society of Rheumatol-
ogy, the Laboratoire Cassenne, France, the Swedish Medical ogy, the Laboratoire Cassenne, France, the Swedish Medical
Research Council, the Medical Faculty of Lund, the Axson Research Council, the Medical Faculty of Lund, the Axson
Johnson, Osterlund, Kock, Nanna Svartz, Crafoord and King Gustaf V 80-year Foundations and the Swedish Arthritis Foundation.

1 Lohmander S, Saxne T, Heinegard DK. Release of cartilage oligomeric matrix protein into joint fluid after knee injury and in osteoarthritis. Ann Rheum Dis 1994;53:8-13

2 Sharif M, Saxne T, Shepstone L, Kirwan JR, Elson CJ, Heinegard D, et al. Relationship between serum cartilage oligomeric matrix protein levels and disease progression in osteoarthritis of the knee joint. Br J Rheumatol 1995;34: 306-10.

3 Petersson IF, Boegard T, Svensson B, Heinegard D, Saxne T. Changes in cartilage and bone metabolism identified by serum markers in early osteoarthritis of the knee joint. Br J Rheumatol 1998;37:46-50.

4 Hedbom E, Antonsson P, Hjerpe A, Aeschlimann D, Paulsson $\mathrm{M}$, Rosapimentel $\mathrm{E}$, et al. Cartilage matrix proteins: an acidic oligomeric protein detected only in cartilage. J Biol Chem1992;267:6132-6.

5 Di Cesare P, Hauser N, Lehman D, Pasumarti S, Paulsson M. Cartilage oligomeric matrix protein (COMP) is an M. Cartilage oligomeric matrix protein (COMP) is an
abundant component of tendon. FEBS Lett 1994;354: 237-40. 
6 Smith RKW, Zunino L, Webbon PM, Bee JA, Heinegard D. Identification of cartilage oligomeric matrix protein (COMP) in equine and bovine tendon. [Abstract]. Trans 41st Annual Meeting Orthopaedic Res Soc 1995:16.

7 Hauser N, Geiss J, Neidhart M, Paulsson M, Häuselmann. Distribution of CMP and COMP in human cartilage. Acta Orthop Scand 1995;66 (suppl 266):71-9.

8 Recklies AD, Baillargeon L, White C. Regulation of cartilage oligomeric matrix protein (COMP) synthesis in human synovial cells and articular chondrocytes. [Abstract]. Arthritis Rheum 1996;39 (suppl):271.

9 Mörgelin M, Heinegard D, Engel J, Paulsson M. Electron microscopy of native cartilage oligomeric matrix protein (COMP) purified from the Swarm rat chondrosarcoma reveals a five-armed structure. J Biol Chem 1992;267: $6137-41$.

10 Oldberg A, Antonsson P, Lindblom K, Heinegard D. Cartilage oligomeric matrix protein (COMP) is structurally lage oligomeric matrix protein (COMP) is structurally
related to the thrombospondins. J Biol Chem 1992;267: related to

11 Dalhberg L, Roos H, Heinegard D, Lark MW, Hoerrner LA, Saxne T, et al. Cartilage metabolism in the injured and uninjured knee of the same patient. Ann Rheum Dis 1994 53:823-7.

12 Forslind K, Eberhardt K, Jonsson A, Saxne T. Increased serum concentrations of cartilage oligomeric matrix protein. A prognostic marker in early rheumatoid arthritis. Br J Rheumatol 1992;31:593-8.

13 Franzèn A, Heinegard D. Isolation and characterization of two sialoproteins present only in bone calcified matrix Biochem J 1985;232:715-24.

14 Hultenby K, Reinholt FP, Norgard M, Oldberg A, Wendel $M$, Heinegard D. Distribution and synthesis of bone sialoprotein in metaphyseal bone of young rats show a distinctly different pattern from that of osteopontin. Eur J Cell Biol 1994;63:230-9.

15 Lohmander S, Saxne T, Heinegard D. Increased concentrations of bone sialoprotein in joint fluid after knee injury. tions of bone sialoprotein in joint

16 Saxne T, Zunino L, Heinegard D. Increased release of bone sialoprotein into synovial fluid reflects tissue destruction in rheumatoid arthritis. Arthritis Rheum 1995;38:82-90.

17 Martel W, Adler RS, Chan K, Niklason L, Helvie MA, Jonsson K. Overview: new methods in imaging osteoarthritis. J Rheumatol 1991;18 (suppl):32-7.

18 Lequesne M, Brandt K, Bellamy N, Moskowitz R, Menkes CJ, Pelletier JP, et al. Guidelines for testing slow acting and disease modifying drugs in osteoarthritis. J Rheumatol 1994;21(suppl 41):65:71

19 Altman RD, Fries JF, Bloch DA, Castens J, Cooke TD, Genant $\mathrm{H}$, et al. Radiographic assessment of progression in osteoarthritis. Arthritis Rheum 1987;30:1214-25.

20 KellgrenJH, Lawrence JS. Radiological assessment of osteoarthrosis. Ann Rheum Dis 1957;16:494-501.

21 Dougados M, Villers C, Amor B. Sensitivity to change of various roentgenological severity scoring systems for osteoathritis of the hip. Rev Rhum Engl Ed 1995;62:169 73.

22 Lane N, Nevitt M, Genant H, Hochberg M. Reliability of new indices of radiographic osteoarthritis of the hand and hip and lumbar disc degeneration. J Rheumatol 1993;20: 1911-18.

23 Spector T, Cooper C, Cushnaghan J, Hart DJ, Dieppe P. Aradiographic atlas of knee osteoarthritis. London: Springe Verlag, 1992:1-15

24 Altman R, Hochberg M, Murphy W, Wolfe F, Lequesne M Atlas of individual radiographic features in osteoarthritis. Osteoarthritis Cartilage 1995;3 (suppl A):3-70.

25 Lynch JA, Buckland-Wright JC MacFardane D. Precision of joint space width measurement in knee osteoarthritis from digital image analysis of high definition macroradiographs. Osteoarthritis Cartilage 1993;1:209-18.

26 Dacre JE, Coppola JS, Herbert KE, Perret D, Huskisson C. Development of a new radiographic scoring system using digital image analysis. Ann Rheum Dis 1989;48:194-200.

27 Buckland-Wright JC. Quantitative radiography of osteoarBuckland-Wright JC. Quantitative radiog
thritis. Ann Rheum Dis 1994;53:268-75.

28 Conrozier T, Tron AM, Balblanc JC, Mathieu P, Piperno M, Fitousi F, et al. Measurement of the hip joint space using
computerized image analysis. Rev Rhum Engl Ed 1993;60: computeriz-11.
29 Conrozier T, Vignon E. Quantitative radiography in osteoarthritis: computerized measurement of radiographic tional methods. Vol 10. Bailleres Clin Rheumatol 1996:42933.

30 Conrozier T,Tron AM, Mathieu P, Vignon E. Quantitative assessment of normal and osteoarthritic hip joint space.Osteoarthritis Cartilage 1995;3 (suppl A):81-8.

31 Conrozier T, Lequesne M, Tron AM, Mathieu P, Berdah L, Vignon E. The effects of the position on the radiographic joint space in osteoarthritis of the hip. Osteoarthritis Cartilage 1997;5:17-22.

32 Lequesne MG, Mery C, Samson M, Gerard P. Indexes of severity for osteoarthritis of the hip and the knee: Validation-value in comparison with other assessment tests. Scand J Rheumatol 1987; (suppl 65):85-9.

33 Ledingham J, Dawson S, Preston B, Milligam G, Doherty $M$. Radiographic progression of hospital referred osteoarthritis of the hip. Ann Rheum Dis 1993;52:263-7.

34 Saxne T, Heinegard D. Cartilage oligomeric matrix protein: A novel marker or cartilage turnover detectable in synovial fluid and blood. Br J Rheumatol 1992;31:583-91.

35 Smith RKW. The nature and role of non collagenous proteins in equine tendon. [Thesis]. London: University of London, 1997.

36 Larsson E, Müssener Å, Heinegård D, Klareskog L, Saxne $T$. Increased serum levels of cartilage oligomeric matrix protein and bone sialoprotein in rats with collagen arthritis. Br J Rheumatol 1997;36:1258-61.

37 Sharif M, George E, Shepstone L, Knudson W, Thonar EJ, Cushnaghan J, et al. Serum hyaluronic acid level as a predictor of disease progression in osteoarthritis of the knee. Arthritis Rheum 1995;38:760-7.

38 Spector TD, Hart DJ, Nandra D, Doyle DV, Mackillop N, Gallimore JR, et al. Low-level increases in serum C-reactive protein are present in early osteoarthritis of the knee and predict progressive disease. Arthritis Rheum 1997;40: $723-7$.

39 Conrozier T, Richard M, Cellier-Chappuis C, Mathieu P, Piperno $M$, Vignon E. Increase of serum $C$ reactive protein in rapidly destructive osteoarthritis of the hip is detectable using high sensitive nephelemetry. [Abstract]. Arthritis Rheum 1997;40 (suppl):S332.

40 Kasugai S, Todescan R, Nagata T, Yao KL, Butler WT, Sodek $\mathrm{J}$, et al. Expression of bone matrix proteins associated with mineralized tissue formation by adult rat bone marrow cells in vitro: inductive effects of dexamethasone on the osteoblasticphentype. J Cell Physiol 1991;147: $116-200$.

41 Oldberg A, Jirskog-Hed B, Axelsson S, Heinegard D. Reguation of bone sialoprotein $\mathrm{mRNA}$ by steroids hormones. J Cell Biol 1989;109:3183-6.

42 Dougados M, Gueguen A, Nguyen M, Berdah L, Lequesne M, Mazieres B, et al. Radiological progression of hip osteoarthritis: definition, risk factors and correlation with clinical status.Ann Rheum Dis 1996;55:356-62.

43 Conrozier T, Jousseaume C, Tron AM, Mathieu P, Caton J, Bejui J, et al. Quantitative measurement of the joint space narrowing progression in hip osteoarthritis. A longitudinal retrospective study of patients treated by total hip arthroplasty. Br J Rheumatol (in press).

44 Tron AM, Conrozier T, Mathieu P, Vignon E.Vitesse de pincement de l'interligne articulaire dans la coxarthrose. Rev Rhum 1994;61:124-30S.

45 Lequesne $M$. Chondrometry. Quantitative evaluation of joint space width and rate of joint space loss in osteoarthristis of the hip. Rev Rhum Engl Ed 1995;62: osteoar $155-8$.

46 Wolfe $\mathrm{F}$. The $\mathrm{C}$ reactive protein but not erythrocyte sedimentation rate is associated with clinical severity in patients with osteoarthritis of the knee or hip. J Rheumatol 1997;24:1486-8.

47 Kobayashi T, Yoshihara Y, Samura A, Yamada H, Shinmei $\mathrm{M}$, Roos $\mathrm{H}$, et al. Synovial fluid concentrations of the C-propeptide of type II collagen correlate with body mass index in primary knee osteoarthritis. Ann Rheum Dis 1997;56:500-3. 